\title{
Shisha Use and Its Associated Factors Among Somali Youth Living in Eastleigh, Nairobi, Kenya
}

\author{
Eunice Jemalel Nyavanga ${ }^{1,2,}$, Maurice Barasa Wafula ${ }^{3}$ \\ ${ }^{1}$ Department of Social and Human Development, Faculty of Social Sciences and Technology, The Technical University of Kenya, Nairobi, \\ Kenya \\ ${ }^{2}$ Malel-Bibwob Clinical Psychologists Consultancy Limited, Nairobi, Kenya \\ ${ }^{3}$ International Planned Parenthood Federation-Africa Regions, Nairobi, Kenya
}

Email address:

enyavanga@yahoo.com (E. J. Nyavanga), emalel.nyavanga@gmail.com (E. J. Nyavanga), barazam@gmail.com (M. B. Wafula), babafraaj@gmail.com (M. B. Wafula)

*Corresponding author

\section{To cite this article:}

Eunice Jemalel Nyavanga, Maurice Barasa Wafula. Shisha Use and Its Associated Factors Among Somali Youth Living in Eastleigh, Nairobi, Kenya. International Journal of Psychological and Brain Sciences. Vol. 3, No. 3, 2018, pp. 22-27. doi: $10.11648 /$ j.ijpbs.20180303.12

Received: June 23, 2018; Accepted: July 16, 2018; Published: August 15, 2018

\begin{abstract}
This study aimed at determining shisha use and its associated factors among Somali Community youth living in Eastleigh in Nairobi. A researcher-developed questionnaire was presented to the participants asking demographic and socioeconomic characteristics with their use of shisha to collect data in selected households. Both descriptive and inferential statistics using SPSS version 23 was used in analyzing data. Findings indicated a high prevalence of shisha use, comorbid use with other psychoactive substances that include khat, other tobacco products, alcoholic beverages and prescription medications. Reasons for use included peer pressure, social acceptability, parental use and affordability. We recommend psychoeducation on the effects of shisha to target both parents and the youth in prevention of shisha use among Somali community.
\end{abstract}

Keywords: Shisha, Psychoactive Substances, Youth, Households, Psychoeducation

\section{Introduction}

Shisha use is now a global public health burden among the youth, [1] that needs to be addressed through surveillance intervention and development of policies that regulate the framework of use, [2]. The geographical spread of shisha use among adolescents and young adults is geographically alarming due to 'café' culture, the rising use of social media, and the Internet and lack of policies that regulate the same. In addition, shisha is being used especially for social gatherings and liked due to its various flavours, [3]. It has also been seen to be growing rapidly in the Eastern Mediterranean countries, [4] and perceived to be less harmful than the other tobacco use, $[4,5]$. The users of shisha believe that when tobacco is filtered, it lowers the risk of tobacco effects, [2, 6, 7]. Furthermore, studies have found it to be common among the Muslim communities compared to other religious populations, [8] and more likely socially acceptable than cigarette smoking, $[2,7,9]$.
Shisha use has been found to be a risk factor for mental health problems especially depression, [10], and physical illnesses that include pulmonary disease, coronary heart disease, and pregnancy complications, [11-12]. A systematic review, Aki et al, 2010 [12] found out that shisha use has a number of health problems that include cancers (lung, bladder, nasopharyngeal, oesophagal cancers), respiratory illness, low birth weight, infertility, and hepatitis $\mathrm{C}$ infection (when used in groups). Second-hand shisha smoke leads to unclean indoor air and occupational safety, [13].

Shisha use has been associated with chewing of Khat (a widespread habit among the Somali community) and has social acceptance specifically among women, [14]. In addition, most shisha users do not even know that shisha has any health risks, $[2,15]$.

Although studies indicate that shisha use is increasing rapidly globally, measures have mostly used university students, [16]. Prevalence is relatively low for certain sub- 
groups and countries not commonly associated with shisha use, [16]. With the above, it is important to determine the prevalence and associated risk factors for shisha use, in this Nairobi suburb that is predominantly occupied by Somali community, who happen to be mostly Muslim.

\section{Methodology and Study Design}

\subsection{Settings and Study Population}

This survey was conducted among young people (between ages 18-25) of Somali Community living in Eastleigh suburb in Nairobi. Eastleigh Section 1 was conveniently sampled because it was learned that in this area has a higher psychoactive use among Somali Community due to a high number of immigrants. This area was learned to have approximately 9.408 households, and 270 households were sampled with the aim of interviewing only one young person per household.

\subsection{Ethical Considerations}

The Kenya Methodist University Ethics Committee approved this study that sets forth research ethics concerning personal data. After this approval, these researchers got authority from the Ministry of Education, (Research Department) and the Nairobi Provincial Administration (Pumwani Division) before collecting data. The researchers explained the purpose, plan and implications of the study to the provincial administration and the participants. A cover letter was obtained from the provincial administration explaining the purpose, plan and implications of the study that was presented to the participants. The participants were also informed that data participation was voluntary, with no payment and they could discontinue at any stage of the study without a penalty. They were also informed that collected data would be kept confidentially, and no names or any other identification data would be recorded and that data analysis would be done in groups but not individually.

\subsection{Study Procedures and Instrumentation}

We visited the sampled households and presented the questionnaires to consenting youth participants. The filled in questionnaires were folded and placed in a sealed box and later transported to the data analysis centre.

\subsection{Data Management and Analysis}

Data were entered into a computer and analysed using SPSS Version 23 to produce both descriptive and inferential statistics. Descriptive statistics indicated family and individual socioeconomic characteristics; use of shisha based on demographic characteristics and comorbidity of shisha and other psychoactive substances. Inferential statistics used chi-square t-test to identify significant variations of the user based on demographic and environmental characteristics.

\section{Result}

\subsection{Family and Individual Social Economic Background of Participants}

This study sought to find out the occupation, living conditions, family income, and marital status of parents and whether participants were born in Eastleigh or elsewhere. The majority (42.7\%), were unemployed while $23.9 \%$ reported they were students and $18.8 \%$ were employed, the self-employed and those engaged in business were $9.4 \%$ and $5.2 \%$ respectively. Most reported to live with parents, $(34.7 \%)$, while $12.2 \%$ live with other relatives, $10.3 \%$ live alone while $9.9 \%$ live with parents and other relatives and $8.0 \%$ live with friends. The majority $70.9 \%$ reported to have moderate family income. $67.1 \%$ had married parents; while $56.8 \%$ reported do have been born in Eastleigh.

Table 1. Indicates family and individual socio-economic background.

\begin{tabular}{|c|c|c|c|}
\hline \multicolumn{2}{|c|}{ Family and Individual Socio-Economic Background } & \multirow{2}{*}{$\begin{array}{l}\text { Count } \\
20\end{array}$} & \multirow{2}{*}{$\begin{array}{l}\text { Column N\% } \\
9.4 \%\end{array}$} \\
\hline \multirow{5}{*}{ Occupation } & Self employed & & \\
\hline & Business & 11 & $5.2 \%$ \\
\hline & Employed & 40 & $18.8 \%$ \\
\hline & Unemployed & 91 & $42.7 \%$ \\
\hline & Student & 51 & $23.9 \%$ \\
\hline \multirow{7}{*}{ Living Conditions } & I live with my parents & 74 & $34.7 \%$ \\
\hline & I live with relatives & 26 & $12.2 \%$ \\
\hline & I live with friends & 17 & $8.0 \%$ \\
\hline & I live alone & 22 & $10.3 \%$ \\
\hline & I live with parents and other relatives & 21 & $9.9 \%$ \\
\hline & I live with spouse/partner & 40 & $18.8 \%$ \\
\hline & Other & 13 & $6.1 \%$ \\
\hline \multirow{6}{*}{ Family income } & Very High & 2 & $.9 \%$ \\
\hline & High & 16 & $7.5 \%$ \\
\hline & Moderate & 151 & $70.9 \%$ \\
\hline & Low & 28 & $13.1 \%$ \\
\hline & Very Low & 11 & $5.2 \%$ \\
\hline & I do not know & 5 & $2.3 \%$ \\
\hline \multirow{2}{*}{ Parents married? } & No & 70 & $32.9 \%$ \\
\hline & Yes & 143 & $67.1 \%$ \\
\hline \multirow{2}{*}{ Born in Eastleigh } & No & 92 & $43.2 \%$ \\
\hline & Yes & 121 & $56.8 \%$ \\
\hline
\end{tabular}




\subsection{Prevalence of Shisha use Per Socio-demographic Characteristics}

Table 2. Shisha use per Socio-demographic Characteristics.

\begin{tabular}{|c|c|c|c|c|c|}
\hline \multirow{3}{*}{ Socio-Demographic Characteristic } & & \multicolumn{4}{|c|}{ Shisha Use } \\
\hline & & \multicolumn{2}{|l|}{ Yes } & \multicolumn{2}{|l|}{ No } \\
\hline & & $\mathbf{n}$ & $\mathbf{N} \%$ & $\mathbf{n}$ & N\% \\
\hline \multirow{3}{*}{ Gender } & Male & 35 & $51.5 \%$ & 89 & $61.4 \%$ \\
\hline & Female & 32 & $47.1 \%$ & 56 & $38.6 \%$ \\
\hline & Other & 1 & $1.5 \%$ & 0 & $0.0 \%$ \\
\hline \multirow{3}{*}{ Age in years } & $18-19$ & 13 & $19.1 \%$ & 39 & $26.9 \%$ \\
\hline & $22-23$ & 17 & $25.0 \%$ & 34 & $23.4 \%$ \\
\hline & $24-25$ & 23 & $33.8 \%$ & 49 & $33.8 \%$ \\
\hline \multirow{2}{*}{ Parents marital Status } & No & 16 & $23.5 \%$ & 54 & $37.2 \%$ \\
\hline & Yes & 52 & $76.5 \%$ & 91 & $62.8 \%$ \\
\hline \multirow{2}{*}{ Born in Eastleigh } & No & 34 & $50.0 \%$ & 58 & $40.0 \%$ \\
\hline & Yes & 34 & $50.0 \%$ & 87 & $60.0 \%$ \\
\hline \multirow{5}{*}{ Highest level of education attained } & Secondary Education & 25 & $36.8 \%$ & 55 & $37.9 \%$ \\
\hline & Middle College Education & 10 & $14.7 \%$ & 5 & $3.4 \%$ \\
\hline & Certificate & 10 & $14.7 \%$ & 16 & $11.0 \%$ \\
\hline & Diploma & 8 & $11.8 \%$ & 25 & $17.2 \%$ \\
\hline & Undergraduate Education & 0 & $0.0 \%$ & 7 & $4.8 \%$ \\
\hline
\end{tabular}

Males indicated a high shisha use of $51.5 \%$ compared to females who reported $57.1 \%$ use. Based on age in years those with higher age bracket of 24-25 and 22-23 indicated a higher use of $33.8 \%$ and $25.0 \%$ compared with lower age bracket of 20-21 and 18-19 that reported $22.1 \%$ use and $19.1 \%$ use. Those whose parents are married has higher shisha use of $76.5 \%$ compared to those whose parents are not married who reported use to be $23.5 \%$. Whether born in or out of Easleigh, both reported same use of $50.0 \%$. Based on Educational level, higher use is among those with secondary education reported use at $36.8 \%$ and primary and below education level of $22.1 \%$ and lower among middle college education, certificate both at $14.7 \%$, diploma at $11.8 \%$ and undergraduate at $0.0 \%$.

\subsection{Comorbidity of Shisha Use and Other Psychoactive Substances in Percentages}

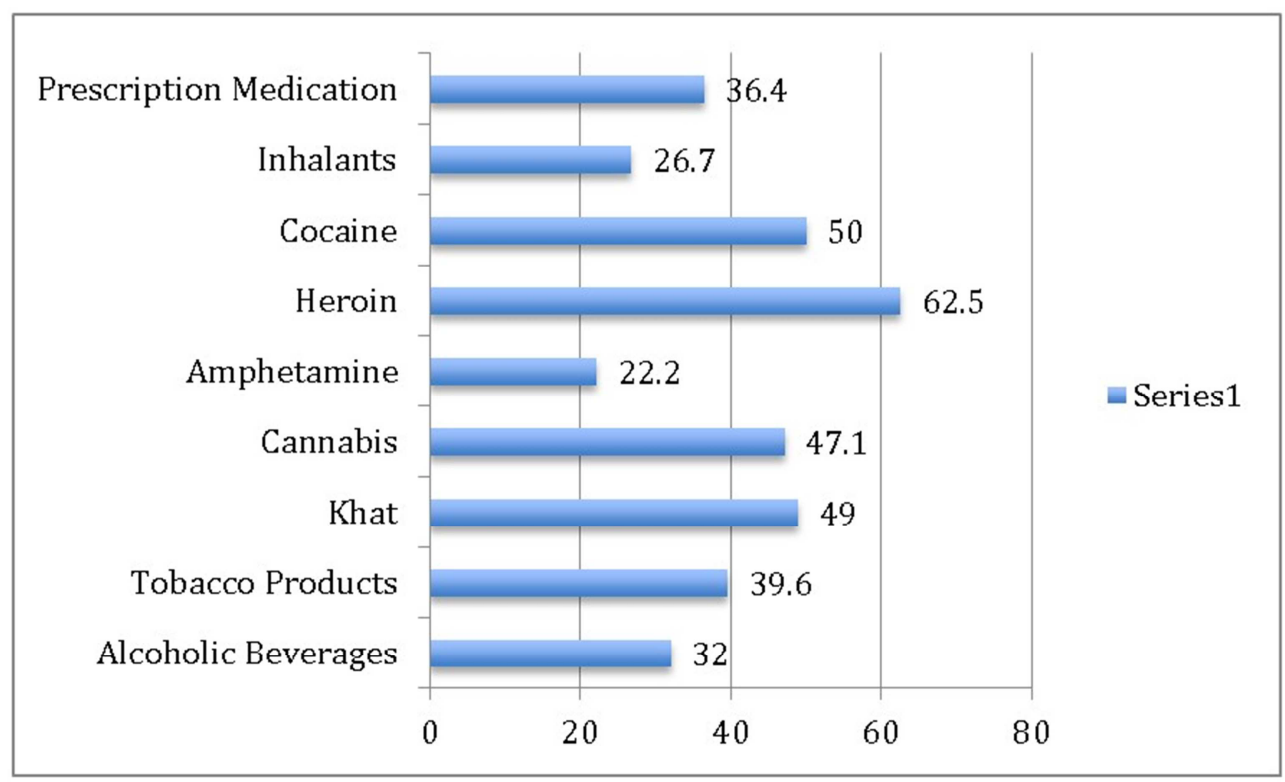

Figure 1. Comorbidity of Shisha use and other Substance Use.

Shisha is used with other psychoactive substances, heroin at $62.50 \%$, cocaine at $50.00 \%$, khat at $49.00 \%$, cannabis at $47.01 \%$, tobacco at $39.60 \%$, prescription medication at $36.40 \%$, alcohol at $32.00 \%$, inhalants at $26.70 \%$ and amphetamine type at $22.20 \%$. 


\subsection{Given Reasons for Shisha Use}

Table 3. Given Reasons for Psychoactive Substance Use.

\begin{tabular}{lcc}
\hline \multicolumn{3}{l}{ Main reason for the using the psychoactive substance use } \\
\hline Peer Pressure & 35 & $66.0 \%$ \\
Socially acceptable & 25 & $41.14 \%$ \\
To exposure to others & 16 & $30.2 \%$ \\
Parental use & 1 & $1.9 \%$ \\
Affordable & 1 & $1.9 \%$ \\
\hline
\end{tabular}

$35(66.0 \%)$ indicated reason for use as peer pressure, $41.14 \%$ cited social acceptability, while $16(30.2 \%)$ indicated exposure from others. Parental use and affordability was I (1.9\%) each.

\section{Discussion}

This study aimed to determine the prevalence and patterns of shisha use among participants.

\subsection{Introduction}

This study found a high return rate of $86.94 \%$. This is in line with other studies among the youth on the prevalence of shisha, [5] which registered a return of $94 \%$. This is attributed to the fact that proper sensitization was given both to the area administration and the participants. The research assistants were also very familiar with the area and could easily reach the participants.

\subsection{Prevalence of Shisha Use}

Shisha use was found to be at $31.9 \%$. This is similar to what was found in a recent study among the youth in the United States, [17] at 38.1\% and that found among Florida high school students $(22.5 \%)$ in 2014, [18]. However, in a study of emerging drugs in Mombasa and Nairobi, Kenya, Kihuthia-Gathu et al 2013 [19] reported that over $25 \%$ of youth between 26-35 years of age abused shisha. This difference could have been due to not including younger youth of between 18-25 years of age and the fact that this study was among a specific population living in a specific area in Nairobi. However, compared to another study in the United States, Primack, et al, 2008 [20] reports a higher prevalence of $40.5 \%$ among university students.

Males were found to have a high of $51.5 \%$ use of shisha compared to the females who reported a higher use of $57.1 \%$. This is similar to other studies globally; $[4,21]$ among school going children in Israel, where $41 \%$ were found to use shisha. Those with a higher age bracket among this group reported a higher shisha use compared to those who are younger.

Those whose parents are married reported a higher (76.5\%) shisha use compared to those whose parents were not married $(23.5 \%)$. No study was identified that indicated marital status of parents and shisha use by these researchers. However, Al-Rawi et al, 2018 [22] found out that parents influenced use at $48.4 \%$ among Dental School Students in the United Arab Emirates. In addition, Varsano et al, 2003 [21], in a study of shisha use in Syria, reported that $40 \%$ of users have parents who are ex-users of shisha, while about $25 \%$ use with parents socially. Those with secondary education had higher shisha use among these participants. Studies have indicated a late onset of shisha use unlike other tobacco use, [18], with about $22.4 \%$ secondary school current use in Florida, USA

\subsection{Comorbidity of Shisha with Other Licit Psychoactive Substances}

This study reported shisha is used with khat at $73.5 \%$. This is in line with other studies. Fufa et al, 2017 [23] reported that undergraduate students of a university in Ethiopia who used shisha also used khat at $36.4 \%$. Findings also indicated that those who used shisha, 52.9\% used other tobacco products. This is similar to other findings, Varsano et al, 2003 [21] among Israel youth, Rath, et al 2012 [24] that reported $30 \%$ tobacco use among youth. Other studies have identified that shisha users are more likely to also smoke other tobacco products, [25-26]. 35.9\% of those who used shisha also used alcohol. This is similar to findings of Shepardon \& Hustad 2016 [26] who reported 11.95\% alcohol use with shisha among college students. However Schilling et al, 2017 [27] associated shisha use with a higher alcohol use of $99.7 \%$ among German University Students. A recent cross-sectional study of factors associated with electronic cigarette, tobacco and conventional cigarette among Australian adolescence, William \& White, 2018 [28] found out that those who used shisha were less likely to use cannabis and alcohol.

\subsection{Given Reasons for Onset Shisha Use}

Some of the reasons given for onset shisha use included peer pressure, (66.0\%), social acceptability, (41.14\%) exposure from others, (30.2\%), parental use and affordability both at $1.9 \%$. Peer pressure was main reason given for shisha use among these participants at (66.0\%). Aki et al, 2013, [9] in a study among school and university students in the Middle East and the Middle East immigrants to the western world, identified peer pressure as one of the reasons this population used shisha. Social acceptability was given as the second reason for shisha use, at $41.14 \%$. This is in line with other studies. Smith et al, 2011 [29] indicated that high school students in San Diego County took shisha because it was more socially acceptable compared to cigarette smoking. $30.2 \%$ reported that they used shisha because of exposure from others. This is in line with findings of Chaouachi, 2009 [30] that pointed out that shisha use among individuals was due to being exposed by others, in most regions.

\section{Conclusion}

Shisha use is prevalent among young adults living in Eastleigh suburb of Nairobi, with males indicating a higher prevalence than females. In addition, higher prevalence is among those whose parents were married, parents were using shisha presently or used before, and those with at least a secondary education. Shisha use was highly used with khat 
and other tobacco products and reasons given for use included peer pressure, social acceptability, exposure from others, parental use and affordability.

\section{Recommendations}

Prevention of shisha use among Somali youth community should target not only the youth but also psychoeducation on the effects of shisha use on both the youth and their parents. Those whose parents use khat and shisha should be the main targets. Other researchers should do more studies on this community on the use of shisha and other psychoactive substances.

\section{References}

[1] Martinasek, M. P., McDermott R. J., Martini L. (2011). Waterpipe (hookah) tobacco smoking among youth. Current Problems in Pediatric and Adolescent Health Care 1; 41 (2): 34-57.

[2] Maziak W, Taleb ZB, Bahelah R, Islam, F., Jaber, R. S., \& Salloum, R. G. (2014). The global epidemiology of waterpipe smoking: Tobacco Control. doi: 10.1136/tobaccocontrol-2014051903 .

[3] Cornacchione, J., Wagoner, K. G., Wiseman, K. D., Kelly, D., Noar, S. M., Smith, M. H., \& Sutfin, E. L. (2016). Adolescent and Young Adult Perceptions of Hookah and Little Cigars/Cigarillos: Implications for Risk Messages. Journal of Health Communication, 21 (7): 818-825, DOI: $10.1080 / 10810730.2016 .1177141$.

[4] Maziak, W., Ward, K. D., \& Eissenburg, T. (2007). Interventions for Waterpipe Smoking Cessation. (Review). The Cochrane Collaborations, John Wiley \& Sons Ltd.

[5] AL-Naggar, R. A. \& Saghir, F. S. A. (2011). Water Pipe (Shisha) Smoking and Associated Factors Among Malaysian University Students Asian Pacific Journal of Cancer Prevention; 12: 3041-3047.

[6] Chaouachi, (2009). Hookah (Shisha, Narghile) Smoking and Environmental Tobacco Smoke (ETS). A Critical Review of the Relevant Literature and the Public Health Consequences. Internaltional Journal of Environmental. Research and. Public Health; 6 (2): 798-843. Doi: 10.3390/ijerph6020798.

[7] Smith, J. R., Novotny, T. E., Edland, S. T. Hofstetter, C. R., Lindsay, S. P., \& Al-Delaimy, W. K. (2011). Determinants of Hookah Use among High School Students, Nicotine \& Tobacco Research; 13 (7): 565-572. https://doi.org/10.1093/ntr/ntr041.

[8] Gupta, P. \& Jain, A. (2016). Assessment of Prevalence, Beliefs, and Habits of Hookah Smoking Among People with a Medical Background Compared to People with a Non-medical Background: A Cross-sectional Self-administered Questionnaire-based Study. Cureus; 8 (8): 1-8. doi: 10.7759/cureus. 735 .

[9] Aki, E. A., Jawad, M., Lam, W. Y., Co, CN., Obeid, R. \& Irani, J. (2013). Motives, beliefs and attitudes towards waterpipe tobacco smoking: a systematic review. Harm Reduction Journal, 10: 12. https://doi.org/10.1186/1477-7517-10-12.

[10] Mossie, A., Kindu, D. \& Negash, A. (2016). Prevalence and
Severity of Depression and Its Association with Substance Use in Jimma Town, Southwest Ethiopia. Depression Research and Treatment; 2016; 1-7. http://dx.doi.org/10.1155/2016/3460462.

[11] Maziak, W., Eissenberg, T., Rastam, S., Hamal, F., Asfar, T. Bachir, M. E., Fouad, M. F., \& Ward, K. D. (2004). Beliefs and attitudes related to narghile (waterpipe) smoking among university students in Syria. Annals of Epidemiology; 14 (9): 646-654. DOI:

https://doi.org/10.1016/j.annepidem.2003.11.003.

[12] Aki, E. A., Gaddam, S., Gunukala, S. K., Honeire, R., Jahaoude, P. A., \& Irani, J. (2010). The effects of waterpipe tobacco smoking on health outcomes: a systematic review. International Journal of Epidemiology; 39 (3): 834-857. https://doi.org/10.1093/ije/dyq002.

[13] Kumar, S. R., Davies, S., Weitzman, M. \& Sherman, S. (2014). A review of air quality, biological indicators and health effects of second-hand water pipe smoke exposure, 0 : 1-6. doi: 10.1136/tobaccocontrol-2014-052038.

[14] Musaiger, A. O. \& AL-Hazzaa, (2012). Prevalence and risk factors associated with nutrition related Non-communicable Diseases in Eastern Mediterranean Region. International Journal of General Medicine, 5: 199-217.

[15] Rawaf, D., Elgindi, A., \& Ismail, S. (2013). Asking the Shisha Question. British Journal of General Practice; 63 (608): 127. DOI: https://doi.org/10.3399/bjgp13X664162.

[16] Morton, J., Song, Y., Foud, H., El Awa, F., Naga, R. A., Zhao, L., Palipudi, K., Asma, S. ((2014). Cross-country comparison of waterpipe use: nationally representative data from 13 low and middle-income countries from the Global Adult Tobacco Survey (GATS). BMJ Journals: Tobacco Control; 25 (5): 419427. http://dx.doi.org/10.1136/tobaccocontrol-2012-050841.

[17] Delnevo, C. D., Gundersen, D. A., Manderski, M. T. B., Giovenco, D. P., Giovino, G. A. (2017). Importance of Survey Design for Studying the Epidemiology of Emerging Tobacco Product Use Among Youth, American Journal of Epidemiology: 186 (4): 405-410. https://doi.org/10.1093/aje/kwx031.

[18] Barnett, T. E., and Livingstone, M. D. (2017). Hookah use among adolescents: Differential cognitions about hookah and cigarettes. Addictive Behaviours; 75: 75-78. https://doi.org/10.1016/j.addbeh.2017.07.007.

[19] Kahuthia-Gathu R, Okwarah, P., Gakunju, R., and Thungu, J. (2013). Trends and emerging drugs in Kenya: A case study in Mombasa and Nairobi County. Journal of Applied Biosciences, 67: 5308-5325. http://dx.doi.o.

[20] Primack, B. A., Sidani, J., Agarwal, A. A., Shadel, W. G., Donny, E. C., \& Eissenberg, T. E. (2008). Prevalence of and Associations with Waterpipe Tobacco Smoking among U.S. University Students, Annals of Behavioral Medicine, 36 (1): 81-86. https://doi.org/10.1007/s12160-008-9047-6.

[21] Varsano, S., Ganz, I., Eldor, N., \& Garenkin, M. (2003). Water-pipe tobacco smoking among school children in Israel: Frequencies, Habits and Attitudes; BMC Public Health, 11: 244. DOI: $10.1186 / 1471-2458-11-244$.

[22] Al-Rawi, N. H., Alnuaimi, A. S., and Uthman, A. T. (2018). Shisha Smoking Habit among Dental School Students in the United Arab Emirates: Enabling Factors and Barriers. International Journal of Dentistry; 2018. doi:10.1155/2018/2805103. 
[23] Fufa, G., Shiferaw, D., Kinati, D., and Desalegn, M. (2017). The Nexus between Khat and Other Drug use among Undergraduate Students of Jigjiga University in Ethiopia; Contributing Factors and Prevalence Rates. Scientific \& Academic Publishing; Public Health Research; 7 (2): 49-54. doi:10.5923/j.phr.20170702.03.

[24] Rath, J. M., Villanti, A. C., Abrams, D. B., Vallone, DM. (2012). Patterns of Tobacco Use and Dual Use in US Young Adults: The Missing Link between Youth Prevention and Adult Cessation. Journal of Environmental and Public Health; 2012: 1-10. http://dx.doi.org/10.1155/2012/679134.

[25] Jordan, H. M., \& Delnevo, C. D. (2010). Emerging tobacco products: Hookah use among New Jersey youth; Preventive Medicine, 51 (5):394-396 https://doi.org/10.1016/j.ypmed.2010.08.016.

[26] Shepardson, R. L. and Hustad, J. T. P. (2015). Hookah Tobacco Smoking During the Transition to College: Prevalence of Other Substance Use and Predictors of Initiation, Nicotine and Tobacco Research; 18 (5): 763-769. https://doi.org/10.1093/ntr/ntv170.
[27] Schilling, L., Zeeb, H., Pischke, C., Helmer, S., SchmidtPokrzywniak, A., Reintjes, R., et al. (2017). Licit and illicit substance use patterns among university students in Germany using cluster analysis. Substance Abuse Treament, Prevention and Policy12: 44. https://doi.org/10.1186/s13011-017-0128-z.

[28] William, T. \& White, V. (2018) What Factors are Associated with Electronic Cigarette, Shisha-Tobacco and Conventional Cigarette Use? Findings from a Cross-Sectional Survey of Australian Adolescents?, Substance Use \& Misuse, DOI: 10.1080/10826084.2017.1411367.

[29] Smith, J. R., Novotny, T. E., Edland, S. D., Hofstetter, C. R., Lidsay, S. P., \& Al-Delaimy, W. K. (2011). Determinants of Hookah Use among High School Students. Niicotine and Tobacco Research, 13 (7): 565-572. 572, https://doi.org/10.1093/ntr/ntr041.

[30] Chaouachi, K. (2009) Hookah (Shisha, Narghile) Smoking and Environmental Tobacco Smoke (ETS). A Critical Review of the Relevant Literature and the Public Health Consequences. International Journal of Environmental Research and Public Health 2009, 6 (2), 798-843; doi: 10.3390/ijerph6020798. 